\title{
Influence of photo-induced degradation on the optoelectronic properties of regioregular poly(3-hexylthiophene)
}

\author{
Yi-Ming Chang ${ }^{\mathrm{a}}$, Wei-Fang Su ${ }^{\mathrm{a}, \mathrm{b}, \mathrm{c}}$, Leeyih Wang ${ }^{\mathrm{a}, \mathrm{b}, *}$ \\ ${ }^{a}$ Institute of Polymer Science and Engineering, National Taiwan University, Taipei 106, Taiwan \\ ${ }^{\mathrm{b}}$ Center for Condensed Matter Sciences, National Taiwan University, Taipei 106, Taiwan \\ ${ }^{\mathrm{c}}$ Department of Materials Science and Engineering, National Taiwan University, Taipei 106, Taiwan
}

Received 9 October 2007; received in revised form 4 January 2008; accepted 5 January 2008

Available online 15 February 2008

\begin{abstract}
Recently, head-to-tail regioregular poly(3-hexylthiophene) (P3HT) has been widely used as an active material in fabricating polymer optoelectronic devices. This study employs UV-vis absorption, photoluminescence (PL), X-ray diffraction (XRD) and the space-charge limited current (SCLC) model to elucidate the effect of light illumination on the optic and optoelectronic properties of P3HT. The degraded performance of P3HT, such as low absorbance, PL emission, and charge-carrier mobility is caused mostly by a reduction in the degree of conjugated structure and the lower crystallinity.
\end{abstract}

(C) 2008 Elsevier B.V. All rights reserved.

Keywords: Poly(3-hexylthiophene); Degradation; Optoelectronic properties; Polymer solar cells

\section{Introduction}

Polymer solar cells have attracted substantial research interest because of their advantages of low cost, large-area fabrication and flexibility [1-5]. In recent years, bulk heterojunction cells using conjugated polymers as the donor and [6,6]-phenyl- $\mathrm{C}_{61}$ butyric acid methyl ester (PCBM) as the accepter have exhibited continued and rapid growth in device efficiency [6-11]. Efficiencies of up to $4-5 \%$ have been achieved by optimizing the fabrication process, such as by annealing devices in a particular range of temperatures [8] or in a microwave oven [9] for an adequate period, or by carefully controlling the solvent evaporation rate [10] to induce the formation of a nanoscaled bi-continuous interpenetrating network to increase exciton dissociation efficiency and the ordered stacking structure of the polymer chains and thereby enhance the charge mobility. Very recently, polymer tandem cells with a power conversion efficiency of up to $6.5 \%$ were also

\footnotetext{
${ }^{*}$ Corresponding author at: Center for Condensed Matter Sciences, National Taiwan University, No. 1, Sec. 4, Roosevelt Rd, Taipei 106, Taiwan. Tel.: + 886233665291 ; fax: +886223696221 .

E-mail address: leewang@ntu.edu.tw (L. Wang).
}

demonstrated using poly[2,6-(4,4-bis-(2-ethylhexyl)-4Hcyclopenta[2,1- $\left.b ; 3,4-b^{\prime}\right]$ dithiophene)-alt-4,7(2,1,3-benzothiadiazole)] and poly(3-hexylthiophene) (P3HT) as the photoactive material of the front and back cells, respectively, to broaden the range of the solar spectrum used [11]. Such progress has led to a large step forward in the practical use of polymer solar cells.

In addition to the fabrication process, the length, conformation and stacking structure of the polymer chains importantly determine the optical properties and carrier mobility of conjugated polymers and therefore influence the performance of their derived devices [12-15]. Nevertheless, the conjugated polymer is a photosensitive material and may degrade in the ambient atmosphere. Exposure of an unencapsulated poly(phenylene vinylene)-based solar cell to light for several hours in an oxygenated atmosphere reduces the cell efficiency severely [16-18]. Although highly stable polymer solar cells with lifetimes of up to $10,000 \mathrm{~h}$ with the careful exclusion of water and oxygen have been reported $[19,20]$, environmental stability remains key to determining the commercialization of polymer solar cells. Additionally, preparing the polymer, including the polymerization, purification and storage processes, in a poor environment, such as under illuminated and oxygen/ 
moisture-filled conditions may somewhat degrade the polymer, reducing device efficiency.

Among conjugated polymers, regioregular P3HT has been utilized intensively as a major ingredient in polymer solar cells [7-13] and polymer field-effect transistors $[21,22]$ because it has high carrier mobility and can easily form highly ordered three-dimensional structures. Some studies of the mechanism of structural decomposition of non-regioregular P3HT during light-induced oxidation have been conducted [23,24]. However, the effect of degradation on the optoelectronic properties of regioregular P3HT has not been discussed. Accordingly, this work aims at investigating the effect of photo-induced degradation on the optoelectronic properties of regioregular P3HT and the performance of P3HT-based photovoltaic cells.

\section{Experimental}

\subsection{Preparation of the illuminated P3HT sample}

Regioregular P3HT was prepared following the Grignard metathesis approach, providing regiocontrol at each coupling step in the polymeric reaction [25]. After polymerization, in a nitrogen atmosphere, the polymer was subjected to Soxhlet extractions with methanol, $n$ hexane, dichloromethane and chloroform, sequentially. Finally, the purified $\mathrm{CH}_{3} \mathrm{Cl}$-soluble $\mathrm{P} 3 \mathrm{HT}$ was stored in a nitrogen-filled glove box. The head-to-tail regioregularity was determined by ${ }^{1} \mathrm{H}-\mathrm{NMR}$ (BRUKER DMX-300 FT-NMR) to be greater than $97 \%$. The number-average molecular weight is $46 \mathrm{~kg} / \mathrm{mol}$ and the polydispersity index is 1.2, based on GPC analysis (THF eluent, polystyrene standard). Then, $100 \mathrm{mg}$ of P3HT was dissolved in $15 \mathrm{~mL}$ of chloroform in an atmosphere of nitrogen. Then, some of the P3HT solution was transferred into an air-filled bottle and illuminated with $100 \mathrm{~mW} / \mathrm{cm}^{2}$ of mercury light for $10 \mathrm{~h}$ in an atmosphere of air (RT, humidity $\sim 70 \%$ ) to form an illuminated P3HT sample (I-P3HT). An OPHIR 2A-SH thermopile detector was used to measure the light intensity.

\subsection{Optical measurements}

UV-vis spectra were obtained on a JASCO V-570 UV/ VIS/NIR spectrophotometer for both P3HT/chloroform solutions and spin-coated films. Photoluminescence (PL) spectra were taken using a Fluorolog-Tau-3 spectrometer (Jobin Yvon) by photo-excitation at the wavelength of $440 \mathrm{~nm}$ for both $\mathrm{P} 3 \mathrm{HT} /$ chloroform solutions and spincoated films. The Fourier transfer infrared (FT-IR) spectra were obtained on a JASCO FT-IR 480 Plus spectrophotometer. The samples were prepared from P3HT/ chloroform solution on $\mathrm{KBr}$ plate by drop-cast method. The X-ray diffraction (XRD) profiles were measured by a BRUKER D8 ADVANCE with $\mathrm{Cu} \mathrm{K} \alpha$ as the incident beam. Data were obtained from $4^{\circ}$ to $25^{\circ}(2 \theta)$ at a scan rate of $0.2 \mathrm{~s} / \mathrm{step}$. The XRD samples were prepared from $\mathrm{P} 3 \mathrm{HT} /$ chloroform solution by drop-cast method and post-treatment at $150{ }^{\circ} \mathrm{C}$ for $30 \mathrm{~min}$ forming a crystalline film.

\subsection{Fabrication of the test devices}

The devices used for space-charge limited current (SCLC) analysis were prepared according to the following procedure. The poly(3,4-ethylenedioxythiophene): poly (styrenesulfonate) (PEDOT:PSS, Baytron P) was spincoated on pre-cleaned ITO glass to modify the surface, affording a hole collection layer of $60 \mathrm{~nm}$ after drying at $140{ }^{\circ} \mathrm{C}$ for $10 \mathrm{~min}$ in air. Then, the device transferred to a nitrogen-filled glove box, the $\mathrm{P} 3 \mathrm{HT} /$ chloroform solution (fresh P3HT or illuminated P3HT) was spin-coated on top of the PEDOT:PSS layer, and annealed at $150^{\circ} \mathrm{C}$ for $30 \mathrm{~min}$. Subsequently, a $100 \mathrm{~nm}$ aluminum electrode was deposited on top of the P3HT: PCBM layer by thermal evaporation.

Photovoltaic devices based on P3HT and PCBM (Nano-C) were fabricated by spin-coating a layer of PEDOT:PSS ( $\sim 40 \mathrm{~nm}$, Baytron P VP AI 4083) on a pre-cleaned ITO glass, drying at $140{ }^{\circ} \mathrm{C}$ for $10 \mathrm{~min}$ in air and transferring into a nitrogen-filled glove box. Then, the P3HT:PCBM chloroform solution which was prepared by mixing either fresh or illuminated P3HT with PCBM at a weight ratio of 1:0.8, was spin-coated on top of the PEDOT:PSS layer. Subsequently, a $150 \mathrm{~nm}$ aluminum electrode was deposited on top of the P3HT:PCBM layer by thermal evaporation. The active area of the device, defined by shadow mask is $0.06 \mathrm{~cm}^{2}$. After cathode being deposited, the devices were annealed at $150^{\circ} \mathrm{C}$ for $20 \mathrm{~min}$ and then slowly cooled to room temperature.

The voltage-current characteristics of the devices were measured using a Keithley $2400 \mathrm{~m}$. The solar simulator was established using an Oriel xenon arc lamp with an AM $1.5 \mathrm{G}$ solar filter, and the $100 \mathrm{~mW} / \mathrm{cm}^{2}$ light intensity was calibrated by a mono-Si reference cell with a KG5 color filter (PV Measurements, Inc.), which had been pre-calibrated by the National Renewable Energy Laboratory. [26]. The thickness of sample was determined by Dektak $6 \mathrm{M}$ profilometer after making a cut on the film surface with a razor blade to expose the substrate.

\section{Results and discussion}

In this experiment, all samples were tested at constant concentration for solutions or at a given thickness for films to compare the optical absorption and PL intensities of fresh P3HT (F-P3HT) and I-P3HT. Fig. 1(a) shows the UV-vis spectra of P3HT samples in chloroform (conc. $=3 \times 10^{-7} \mathrm{M}$ ). In a conjugated polymer, the extent of conjugation directly affects the observed energy of the $\pi-\pi^{*}$ transition, which appears as the maximum absorption $\left(\lambda_{\max }\right)$ in the UV-vis spectrum of polymer solution. The 
a

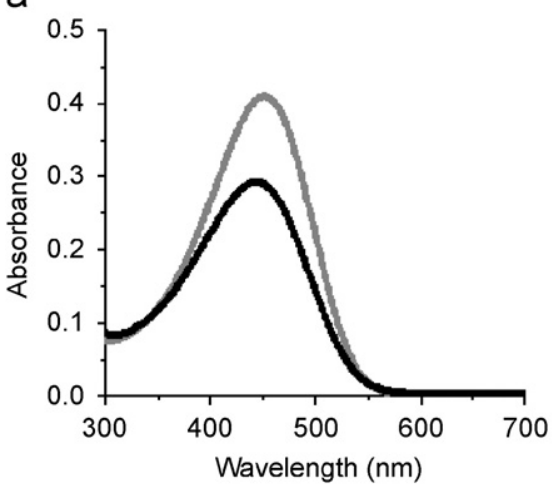

b

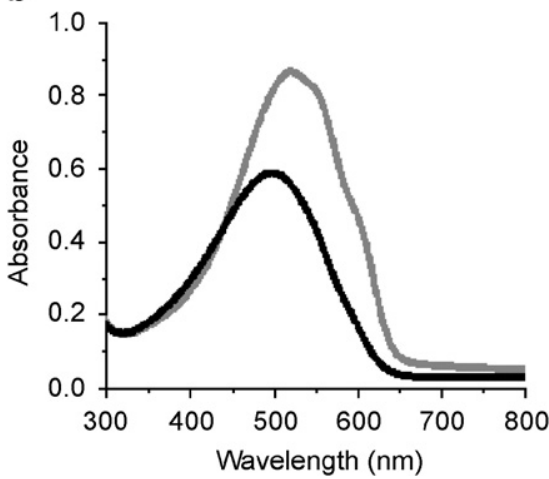

C

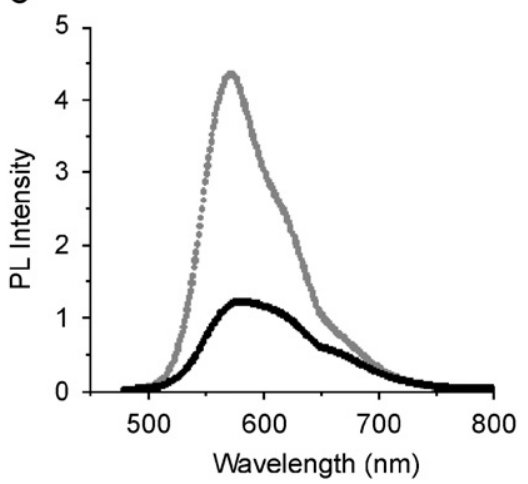

d

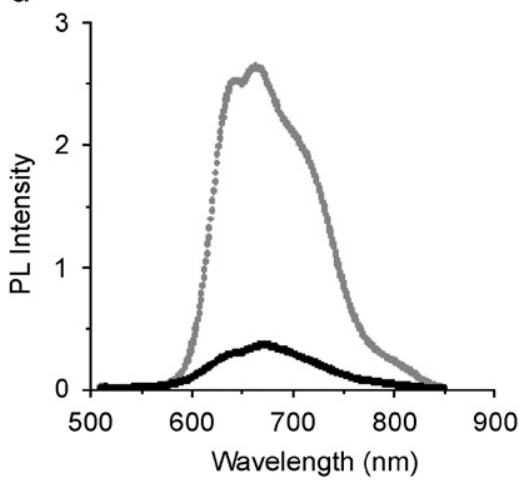

Fig. 1. UV-vis spectra of (a) P3HT solution and (b) P3HT films and their PL spectra of (c) P3HT solution and (d) P3HT films. Gray line: F-P3HT; Black line: I-P3HT. The PL measurement was at $440 \mathrm{~nm}$ of excitation wavelength for both P3HT solution and P3HT films.

$\lambda_{\max }$ values for F-P3HT and I-P3HT are 452 and $444 \mathrm{~nm}$, respectively. I-P3HT exhibits an $8 \mathrm{~nm}$ blue shift from that of F-P3HT; this blue shift indicates that the photo-induced effect in an atmosphere of air reduces the conjugation length of P3HT. Moreover, the absorbance of I-P3HT at $444 \mathrm{~nm}$ is $30 \%$ lower than that of F-P3HT at $452 \mathrm{~nm}$. The absorbance declines from 0.40 to 0.29 . This drop can occur if the conjugation length is affected by the degradation mechanism in P3HT because of the broken, non-continuous conjugated structure. Fig. 1(b) presents the UV-vis spectra of the polymer films. The F-P3HT exhibits a peak at $520 \mathrm{~nm}$ and two shoulders at 550 and $610 \mathrm{~nm}$, which can be attributed to the crystalline $\pi$-stacking structure of P3HT [13,27]. Evidently, in a manner similar to the solution state, I-P3HT has a lower absorbance than F-P3HT, and the $\lambda_{\max }$ of I-P3HT is $22 \mathrm{~nm}$ blue-shifted from that of F-P3HT (shifted from 520 to $498 \mathrm{~nm}$ ), and the crystalline $\pi$-stacking peak becomes unnoticeable. This result can be explained by a change in the stacking conformation of the polymer structure from high crystallinity to lower crystallinity, and a reduction of intraplane and interplane stacking, which causes a poor $\pi-\pi^{*}$ transition and lower absorbance.

As shown in Figs. 1(c) and (d), the I-P3HT exhibits significantly less emission than F-P3HT both in solution and as a film. Two causes may contribute to this reduction in PL intensity. The first is the lower optical absorption of

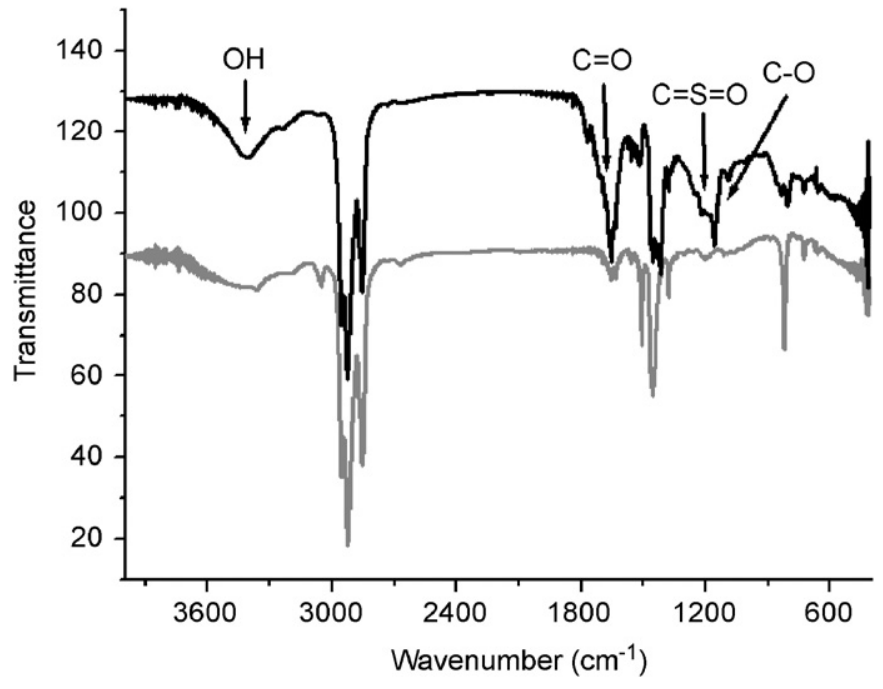

Fig. 2. FT-IR spectra of F-P3HT (gray line) and I-P3HT (black line).

I-P3HT and the fewer excitations that result in a lower PL intensity. A second cause is evidenced by the FTIR spectrum of I-P3HT, displayed in Fig. 2. The oxidation degradation yields $\mathrm{C}=\mathrm{O}\left(1710,1685 \mathrm{~cm}^{-1}\right), \mathrm{C}=\mathrm{S}=\mathrm{O}$ $\left(1253,1226 \mathrm{~cm}^{-1}\right)$ and $\mathrm{C}-\mathrm{O}\left(1154 \mathrm{~cm}^{-1}\right)$ moieties $[23,28]$ in P3HT upon light illumination. These undesirable polar groups may act as carrier quencher and reduce the emission intensity. 
a

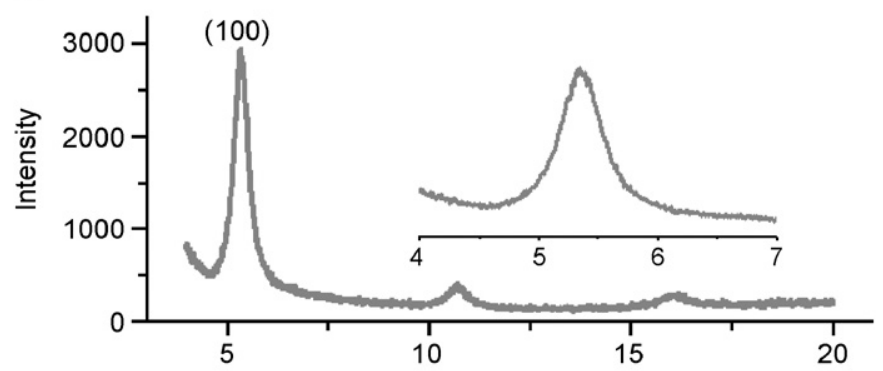

b

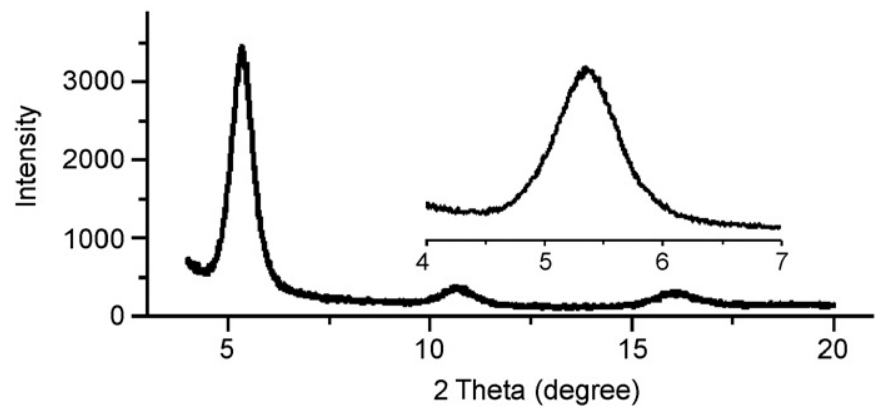

Fig. 3. XRD profiles of (a) F-P3HT and (b) I-P3HT drop-cast films; the inset shown the main peak and its FWHM at range of $4-7^{\circ}(2 \theta)$.

Fig. 3 presents the XRD patterns of drop-cast films. The main (100) diffraction peaks are observed, corresponding to an ordered, self-organized lamellae structure with an interlayer spacing, which is formed by parallel stacks of polymer main chains that are separated by regions that are filled with the alkyl side-chains. The $d$-spacing values can be calculated using Bragg's equation, $n \lambda=2 d \sin \theta$. The XRD patterns of F-P3HT and I-P3HT with first-order reflections at $2 \theta$ angles of $5.34^{\circ}$ and $5.35^{\circ}$ correspond to interlayer $d$-spacings of 16.6 and $16.5 \AA$, respectively. Moreover, Scherrer's equation $(D=0.9 \lambda / \beta \cos \theta)$ with the full width at half maximum (FWHM) of main the diffraction peaks of the P3HT revealed that the sizes of crystals in F-P3HT and I-P3HT are 308 and $221 \AA$, respectively. This result proves that I-P3HT has lower crystallinity than F-P3HT.

For optoelectronic applications such as field-effect transistors and photovoltaic cells, the hole mobility in conjugated polymer is a key parameter in determining device performance. This work applied the hole-injection diode structure of ITO/PEDOT:PSS/P3HT/aluminum to measure the hole mobility in P3HT using the SCLC model $[15,29]$.

When a voltage was applied to the device, accumulated space charges limited the transport of holes through the polymer film; the current density in SCLC is given by

$J=\frac{9}{8} \varepsilon_{r} \varepsilon_{0} \mu_{h 0} \frac{V^{2}}{L^{3}} \exp \left(0.89 \sqrt{\frac{V}{E_{0} L}}\right)$,

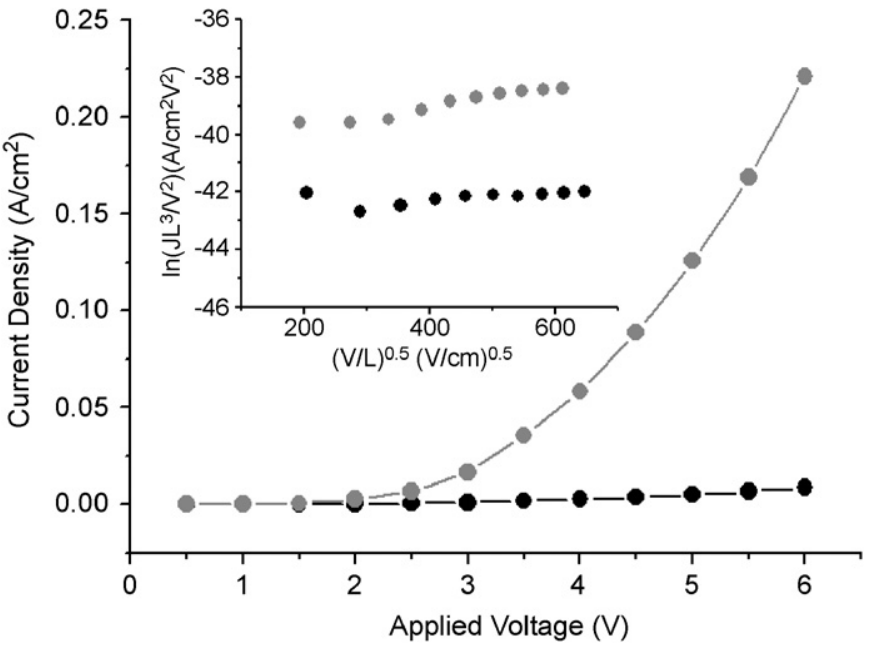

Fig. 4. $I-V$ characteristics of ITO/PEDOT:PSS/F-P3HT/Al (gray line) and ITO/PEDOT:PSS/I-P3HT/Al (black line); the inset shown the plots of $\ln \left(J L^{3} / V^{2}\right)$ versus $(V / L)^{0.5}$

where $\varepsilon_{r}$ is the dielectric constant of the polymer, $\varepsilon_{0}$ is the permittivity of free space, $\mu_{h 0}$ is the zero-field hole mobility, $V$ denotes the voltage drop across the device, $L$ is the thickness of P3HT, and $E_{0}$ is the characteristic field. Fig. 4 plots the current density against the applied voltage of devices ITO/PEDOT:PSS/F-P3HT/Al and ITO/PEDOT:PSS/I-P3HT/A1, respectively. F-P3HT has a current density of $0.13 \mathrm{~A} / \mathrm{cm}^{2}$ at $5 \mathrm{~V}$, while that of I-P3HT is only $0.005 \mathrm{~A} / \mathrm{cm}^{2}$ at $5 \mathrm{~V}$, indicating that the I-P3HT device exhibits a much lower injection current than the F-P3HT device. Furthermore, the current density is plotted against the applied voltage as $\ln \left(J L^{3} / V^{2}\right)$ versus $(V / L)^{0.5}$ in the inset of Fig. 4. The zero-field hole mobilities of F-P3HT and I-P3HT, which can be calculated from the intercepts, are $1.6 \times 10^{-5} \mathrm{~cm}^{2} / \mathrm{V} \mathrm{s} \quad\left(E_{0}=1.4 \times 10^{5} \mathrm{~V} / \mathrm{cm}\right)$ and $7.7 \times 10^{-7} \mathrm{~cm}^{2} / \mathrm{V} \mathrm{s}\left(E_{0}=4.0 \times 10^{5} \mathrm{~V} / \mathrm{cm}\right)$, respectively. These results demonstrate that the light illumination process strongly reduces the hole mobility of P3HT. The lower mobility may be explained by the UV-vis and XRD results of the polymer film, which show a change in the chain stacking conformation of P3HT from high crystallinity to a lower crystallinity. Another possibility involves a photo-induced degradation reaction on the P3HT. Consistent with the PL results discussed earlier, the polar groups may also trap carriers and thus influence the transport of charges in the polymer.

The $I-V$ curves of photovoltaic cells based on F-P3HT and I-P3HT were shown in Fig. 5. The F-P3HT device showed a comparable photovoltaic behavior as those reported elsewhere [7,9,10] with an open-circuit voltage $\left(V_{\mathrm{oc}}\right)$, short-circuit current density $\left(J_{\mathrm{sc}}\right)$, fill factor $(\mathrm{FF})$, and power conversion efficiency $(\eta)$ of $0.64 \mathrm{~V}, 10.4 \mathrm{~mA} / \mathrm{cm}^{2}, 54.0 \%$, and $3.59 \%$, respectively. In contrast, the I-P3HT device demonstrated substantially reduced performance: $V_{\mathrm{oc}}=0.57 \mathrm{~V}, J_{\mathrm{sc}}=6.32 \mathrm{~mA} / \mathrm{cm}^{2}$, $\mathrm{FF}=39.8 \%$, and $\eta=1.43 \%$. Obviously, the decrease 


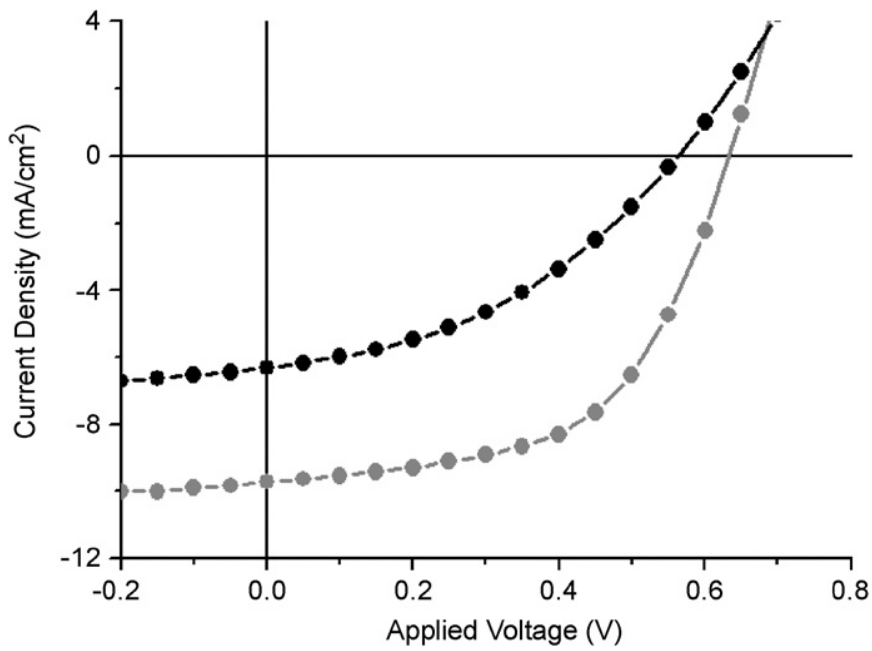

Fig. 5. $I-V$ characteristics of photovoltaic cells based on F-P3HT: PCBM (gray line) and I-P3HT:PCBM (black line) measured under the $100 \mathrm{~mW} / \mathrm{cm}^{2}$ of $\mathrm{AM} 1.5 \mathrm{G}$ irradiation.

in photocurrent and FF was the major contribution to the decline of device efficiency, indicating the poor cell performance was attributed to the drop of hole mobility resulting from the decrease of polymer crystallinity and light absorption coefficient and the raise of carrier quencher concentration upon the degradation of P3HT.

\section{Conclusions}

The light illumination of P3HT in air will result in the oxidation degradation of polymer and the formation of polar functional groups, thus potentially reducing the conjugation length, the absorption/emission intensities, the size of the crystal domain and the charge-carrier mobility. These effects can lead to the poor performance of P3HTbased optoelectronic devices. Therefore, the development of efficient organic solar cells or transistors based on P3HT depends not only on fabrication in an inert atmosphere, but also on the synthesis and storage of material in a suitable environment, such as a dark or inert environment, to ensure polymer quality.

\section{Acknowledgments}

We would like to thank National Taiwan University, Academia Sinica and the National Science Council of Taiwan, Republic of China, for financially supporting this research.

\section{References}

[1] H. Spanggaard, F.C. Krebs, Sol. Energy Mater. Sol. Cells 83 (2004) 125.

[2] E. Bundgaard, F.C. Krebs, Sol. Energy Mater. Sol. Cells 91 (2007) 954.

[3] S. Günes, H. Neugebauer, N.S. Sariciftci, Chem. Rev. 107 (2007) 1324.

[4] F.C. Krebs, J. Alstrup, H. Spanggaard, K. Larsen, E. Kold, Sol. Energy Mater. Sol. Cells 83 (2004) 293.

[5] F.C. Krebs, H. Spanggaard, T. Kjær, M. Biancardo, J. Alstrup, Mater. Sci. Eng. B 138 (2007) 106.

[6] S.E. Shaheen, C.J. Brabec, N.S. Sariciftci, F. Padinger, T. Fromherz, J.C. Hummelen, Appl. Phys. Lett. 78 (2001) 841.

[7] F. Padinger, R.S. Rittberger, N.S. Sariciftci, Adv. Funct. Mater. 13 (2003) 85

[8] W. Ma, C.Y. Yang, X. Gong, K. Lee, A.J. Heeger, Adv. Funct. Mater. 15 (2005) 1617.

[9] C.J. Ko, Y.K. Lin, F.C. Chen, Adv. Mater. 19 (2007) 3520.

[10] G. Li, V. Shrotriya, J. Huang, Y. Yao, T. Moriarty, K. Emery, Y. Yang, Nat. Mater. 4 (2005) 864.

[11] J.Y. Kim, K. Lee, N.E. Coates, D. Moses, T.Q. Nguyen, M. Dante, A.J. Heeger, Science 317 (2007) 222.

[12] W. Ma, J.Y. Kim, K. Lee, A.J. Heeger, Macromol. Rapid Commun. 28 (2007) 1776.

[13] Y. Kim, S. Cook, S.M. Tuladhar, S.A. Choulis, J. Nelson, J.R. Durrant, D.D.C. Bradley, M. Giles, I. McCulloch, C.S. Ha, M. Ree, Nat. Mater. 5 (2006) 197.

[14] E.J. Zhou, Z. Tan, C.H. Yang, Y.F. Li, Macromol. Rapid. Commun. 27 (2006) 793.

[15] C. Goh, R.J. Kline, M.D. McGehee, E.N. Kadnikova, J.M.J. Fréchet, Appl. Phys. Lett. 86 (2005) 122110.

[16] F.C. Krebs, J.E. Carlé, N. Cruys-Bagger, M. Andersen, M.R. Lilliedal, M.A. Hammond, S. Hvidt, Sol. Energy Mater. Sol. Cells 86 (2005) 499.

[17] K. Kawano, R. Pacios, D. Poplavskyy, J. Nelson, D.D.C. Bradley, J.R. Durrant, Sol. Energy Mater. Sol. Cells 90 (2006) 3520.

[18] R. Pacios, A.J. Chatten, K. Kawano, J.R. Durrant, D.D.C. Bradley, J. Nelson, Adv. Funct. Mater. 16 (2006) 2117.

[19] F.C. Krebs, H. Spanggaard, Chem. Mater. 17 (2005) 5235.

[20] F.C. Krebs, K. Norrman, Prog. Photovolt.: Res. Appl. 15 (2007) 697.

[21] R.J. Kline, M.D. McGehee, M.F. Toney, Nat. Mater. 5 (2006) 222.

[22] H. Sirringhaus, P.J. Brown, R.H. Friend, M.M. Nielsen, K. Bechgaard, B.M.W. Langeveld-Voss, A.J.H. Spiering, R.A.J. Janssen, E.W. Meijer, D.M. de Leeuw, Nature 401 (1999) 685.

[23] M.S.A. Abdou, S. Holdcroft, Macromolecules 26 (1993) 2954.

[24] B.H. Cumpston, K.F. Jensen, Trends Polym. Sci. 4 (1996) 151.

[25] R.S. Loewe, S.M. Khersonsky, R.D. McCullough, Adv. Mater. 11 (1999) 250.

[26] V. Shrotriya, G. Li, Y. Yao, T. Moriarty, K. Emery, Y. Yang, Adv. Funct. Mater. 16 (2006) 2016.

[27] P.J. Brown, D.S. Thomas, A. Köhler, J.S. Wilson, J.S. Kim, C.M. Ramsdale, H. Sirringhaus, R.H. Friend, Phys. Rev. B 67 (2003) 064203.

[28] D.L. Pavia, G.M. Lampman, G.S. Kriz, Introduction to Spectroscopy: A Guide for Students of Organic Chemistry, Harcourt Brace College Publishers, Fort Worth, 1996.

[29] L.S. Roman, O. Inganäs, Synth. Met. 125 (2002) 419. 